\title{
EL ESTUDIO DE LA ORALIDAD \\ DESDE UNA PERSPECTIVA ETNOGRÁFICA
}

Amparo Tuson Valls

Universitat Autònoma de Barcelona

\section{INTRODUCCIÓN}

En primer lugar, quiero felicitar a quienes han organizado este simposium por el título "Perspectivas sobre a oralidade". A menudo eventos semejantes llevan por título algo que incluye "lengua oral", por ejemplo "El estudio de la lengua oral". Pero decir "lengua oral" es como decir "sube arriba", "baja abajo" o "entra dentro": es una redundancia. ¿Por qué? Porque la lengua es "oral", la oralidad es la esencia y la existencia de las lenguas. Y si alguien tiene alguna duda al respecto, que mire la historia de la humanidad o la historia del individuo. Pasaron cientos de miles de años antes de que los seres humanos —que desde que lo son hablan - inventaran la escritura, allá por el 4000 antes de nuestra era. Y la extensión de la escritura ha sido lenta y aún hoy existen cientos de comunidades — que por supuesto hablan — cuyas lenguas no tienen un código escrito, porque esas comunidades no lo necesitan para vivir, y existen millones de personas que no conocen, no dominan o no usan habitualmente la escritura.

\section{2. ¿POR QUÉ ESTUDIAR LA ORALIDAD y, MÁS EN CONCRETO,} LA CONVERSACIÓN?

Porque es la forma universal en que existe la lengua. Todas las personas, pertenezcan a la cultura que pertenezcan, conversan. La conversación es, podríamos decir el "protogénero" discursivo, la forma primera y primaria en que se manifiesta, en que existe, la lengua (Tuson 1995).

En los primeros años de nuestras vidas adquirimos la lengua o las lenguas de nuestro entorno de forma natural, por el simple hecho de vivir en un medio en que la gente conversa; la adquisición lingüística es parte del proceso de socialización. A través de la conversación los seres humanos aprendemos a nombrar el mundo, a relacionarnos con las personas que tenemos alrededor, y 
así vamos construyendo nuestras identidades sociales. Más tarde, la escuela — en el caso de que vayamos a la escuela — se encargará de introducirnos —a través de un aprendizaje formal— en otras formas más elaboradas de la oralidad, como debates, exposiciones, y, por supuesto, en el código escrito.

Curiosamente, el interés por el estudio de la conversación no empezó dentro del ámbito de la lingüística, sino en el seno de la antropología y de la filosofía. Las tradiciones en el estudio lingüístico — gramatical e inmanentista- han sido y son todavía tan fuertes que aún hoy se encuentran resistencias y reticencias hacia los estudios de la conversación espontánea. En parte, porque se sigue con la idea de que los usos orales cotidianos son algo caótico que difícilmente se puede analizar. Sin embargo, ya hace muchos años, en la primera mitad del siglo XX, los antropólogos lingüistas Boas (1911) y Sapir (1949 [1932]) señalaban que si de verdad queremos entender la cultura de un pueblo hemos de observar las conversaciones, y el filósofo del lenguaje Wittgenstein afirmaba que "el lenguaje ordinario está perfectamente en orden". Otra cosa es que las limitaciones de la mente humana y el desarrollo de la tecnología hayan impedido hasta hace poco recoger adecuadamente y analizar algo que, eso sí, sin duda, es complejo y multidimensional.

\section{CARACTERÍSTICAS DE LA CONVERSACIÓN ESPONTÁNEA}

En un artículo del año 1974, Sacks, Schegelof y Jefferson, desde la sociología de la interacción (etnometodología), señalaban las características de las conversaciones espontáneas:

1. El cambio de hablante es recurrente o, al menos, se produce. Es decir, una de las características de la conversación es que es dialogal.

2. En general, no habla más de una persona a la vez.

3. Los solapamientos (dos —o más- participantes hablando a la vez) son comunes pero breves.

4. Las transiciones más comunes entre un turno de palabra y el siguiente son las que se producen sin intervalos ni solapamientos, o las que se producen con un breve intervalo.

5. El orden de los turnos de palabra no es fijo.

6. La duración de los turnos de palabra no es fija, si bien se tiende a un cierto equilibrio.

7. La duración de una conversación no se especifica previamente.

8. Lo que dicen los hablantes no se ha especificado previamente.

9. La distribución de los turnos de palabra no se ha especificado previamente. 
10. El número de hablantes puede variar.

11. El discurso puede ser continuo o discontinuo.

12. Existen técnicas para la distribución de los turnos.

13. Se utilizan diferentes unidades formales de construcción de los turnos (una palabra, una frase, una oración, etc.).

14. Existen mecanismos para reparar los errores o las transgresiones en la toma de la palabra.

A partir de esas características, lo que queda claro es que la conversación es algo impreciso, delicado, frágil, sujeto a normas muy flexibles que se van actualizando y negociando en el mismo proceso conversacional. Todo ello nos puede hacer pensar que casi parece un milagro que nos lleguemos a entender y, sin embargo, más o menos, nos vamos entendiendo y conversamos sin pensar demasiado lo que decimos y lo que interpretamos de lo que nos dicen las otras personas.

\section{4. ¿CÓMO ESTUDIAR LA ORALIDAD Y, MÁS CONCRETAMENTE, LA CONVERSACIÓN?}

Lógicamente, para analizar una conversación lo primero que hay que hacer es grabarla. Eso ya requiere tomar una serie de decisiones no siempre fáciles: ¿la grabaremos sólo en audio o en vídeo? ¿Cómo hacerlo? La ética nos indica que quienes conversan han de saber que se les graba ¿Lo diremos antes o después de la grabación? ¿Cómo pediremos permiso?

Una vez tenemos la grabación, hemos de proceder a transcribirla. Y eso también es muy complejo. Hemos de decidir qué tipo de transcripción utilizaremos; más o menos detallada, incorporando indicaciones sobre la prosodia, sobre los comportamientos no verbales, haciendo una descripción previa de las personas que conversan, del contexto en el que se produce... La transcripción es el primer paso del análisis porque las decisiones que tomemos necesariamente condicionarán lo que luego podamos observar, describir y analizar.

A la hora de describir y analizar la conversación necesitamos responder a una serie de preguntas:

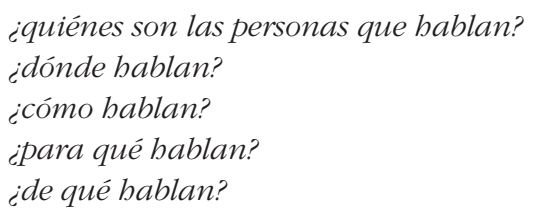


Para responder a todas estas preguntas, la etnografía de la comunicación nos ofrece unos instrumentos que nos permiten analizar algo tan cotidiano y a la vez tan complejo como una conversación (o cualquier otro tipo de interacción oral) con todo detalle.

\section{LA PERSPECTIVA ETNOGRÁFICA}

Los presupuestos básicos de la Etnografía de la comunicación consisten en una manera especial de mirar las lenguas, sus usos y a sus usuarios. Se considera que la lengua es en tanto que es usada y, como tal, es parte y síntoma de la realidad cultural de los pueblos.

Además, se parte del hecho incontestable de que el uso lingüístico es diverso, heterogéneo — como lo son los grupos sociales-. En cuanto a la comunicación, se entiende como acción entre individuos, entre seres sociales; de ahí que se dé una importancia crucial al estudio de la interacción humana.

El objeto de estudio de la etnografía de la comunicación es la competencia comunicativa, entendida como parte, una parte fundamental, de la competencia cultural. Goodenough, un antropólogo clásico, definía así, en 1957, la "competencia cultural": "Todo aquello que hay que saber para funcionar de manera aceptable para los miembros [de una comunidad] y hacerlo en cualquier papel que acepten para ellos mismos" (Goodenough 1964 [1957]).

Y es evidente que para funcionar de manera aceptable en el seno de un grupo humano — además de saber cómo comer y qué comer, cómo vestirse, etc.-, implica saber cómo moverse comunicativamente. De ahí surge la necesidad de acuñar y definir el concepto de competencia comunicativa.

Saville-Troike, especifica de la siguiente manera todo lo que incluye el concepto de competencia comunicativa:

[La competencia comunicativa] Implica conocer no sólo el código lingüístico, sino también qué decir a quién, y cómo decirlo de manera apropiada en cualquier situación dada. Tiene que ver con el conocimiento social y cultural que se les supone a los hablantes y que les permite usar e interpretar las formas lingüísticas. [...] La competencia comunicativa incluye tanto el conocimiento como las expectativas respecto a quién puede o no puede hablar en determinados contextos, cuándo hay que hablar y cuándo hay que guardar silencio, a quién se puede hablar, cómo se puede hablar a personas de diferentes estatus y roles, cuáles son los comportamientos no verbales adecuados en diferentes contextos, cuáles son las rutinas para tomar la palabra en una conversación, cómo preguntar y proveer in- 
formación, cómo pedir, cómo ofrecer o declinar ayuda o cooperación, cómo dar órdenes, cómo imponer disciplina, etc. En pocas palabras, todo aquello que implica el uso lingüístico en un contexto social determinado. (Saville-Troike 1989 [1982]).

Resulta evidente la gran complejidad de lo que se quiere estudiar, ya que la competencia comunicativa incluye la competencia lingüística pero va más allá incluyendo todo aquello que se pone en funcionamiento en cualquier interacción comunicativa oral, tanto lo verbal como lo no verbal.

Pero, ¿cómo se adquiere y se desarrolla la competencia comunicativa?

En parte de forma explícita. Podemos reconocer determinadas expresiones en las que, desde la infancia, se nos van transmitiendo las normas de comportamiento comunicativo que funcionan en nuestro entorno. Por ejemplo:

\author{
A los mayores no se les interrumpe \\ No bables con la boca llena \\ No se puede hablar mientras se come \\ No levantes la voz a tu madre \\ Espera a que te pregunten \\ Levanta la mano para hablar \\ Contesta cuando te hablan
}

Pero, también —y muy especialmente-, se adquiere y se desarrolla de forma implícita, por el mero hecho de vivir en un entorno en que la gente se comunica en diferentes situaciones. Veamos el siguiente ejemplo, tomado del analista del discurso francés Patrick Charaudeau:

Yo puedo salir a la calle y, acercándome a un perfecto desconocido, decirle: Perdone, ¿me puede decir dónde está plaza del Obradoiro?

Resultaría más extraño que le dijera: *Perdone, me llamo Amparo Tusón, ¿me puede decir dónde está la plaza del Obradoiro?

Pero sin duda, resultaría del todo inadecuado que le dijera: **Perdone, me llamo Amparo Tusón, ¿me puede decir dónde está el Golfo Pérsico?

¿Quién y cuándo nos ha dicho qué se puede preguntar a una persona desconocida en una situación como ésa? Y es que la adquisición de la competencia comunicativa es una parte esencial del proceso de socialización y puede no acabar nunca. Porque en cuanto nos encontramos en una situación nueva, en un país diferente, en un trabajo distinto, hemos de ir desarrollando aspectos nuevos de esa competencia. 


\section{LOS COMPONENTES DEL EVENTO COMUNICATIVO}

Hymes (1972), basándose en aportaciones anteriores —y muy especialmente en el esquema de la comunicación de Jakobson (1984 [1960])— propone una guía para el estudio de cualquier evento comunicativo, desde una conversación espontánea hasta un juicio o un ritual religioso. Como Hymes pretende que, a través de esta guía, se pueda llevar a cabo una observación y un análisis muy fino y detallado, presenta ocho elementos que están presentes en todo evento comunicativo. Es lo que se conoce como el modelo SPEAKING, debido a que, en inglés, las iniciales de los ocho componentes forman este acróstico Situation, Participants, Ends, Act sequences, Key, Instrumentalities, Norms y Genre (Situación, participantes, finalidades, secuencia de actos, clave, instrumentos, normas y género).

Lo que define al evento es que es imprescindible el uso de la palabra para que se realice y, también, que se suele asociar a un tiempo y a un espacio apropiados o que se pueden constituir como tales al celebrarse en ellos tal acontecimiento. Además, para cada acontecimiento comunicativo quienes participan en él se supone que lo hacen a partir de unos estatus y papeles característicos, utilizan instrumentos verbales y no verbales apropiados, organizan el evento en secuencias y actúan en el tono o clave también apropiados para los fines que pretenden, respetan o transgreden unas normas de interacción que regulan cómo se toma la palabra, si se puede interrumpir o no, etc. y se guían por unas normas de interpretación que les permiten dar sentido a lo que se dice aunque sea de forma indirecta o implícita, normas que, desde luego, se pueden transgredir o aplicar de forma equivocada, dando lugar a malentendidos o a equívocos — deseados o no-. Todo este conjunto de componentes no se disponen arbitrariamente en cada ocasión sino que a través de las prácticas sociales se van constituyendo en géneros identificables por unas pautas y unas convenciones que los hablantes siguen y reconocen, según el evento comunicativo de que se trate. Ejemplos de géneros son la conferencia, el sermón, la entrevista radiofónica o el debate televisivo, el trabajo en grupo o la explicación en un aula, etc., géneros que, como dije al principio, derivan del "protogénero" que es la conversación espontánea. Esta propuesta de descripción y análisis es muy útil porque permite utilizarla como marco donde incluir las aportaciones que se han hecho desde muchas disciplinas como el análisis de la conversación, la etnometodología, la pragmática o el análisis del discurso (Calsamiglia \& Tusón 2007 [1999]).

Como no quiero excederme en el tiempo que me ha sido asignado, me voy a dedicar a algunos de ellos que me parecen especialmente interesantes. En primer lugar, la situación. Como Hymes quiere ser muy detallado, muy minucioso, en muchos casos — como el que ahora nos ocupa - cada com- 
ponente se divide en varios subcomponentes, en este caso en dos. Por una parte, tendremos la localización espacial y temporal, el lugar y el momento donde se produce un evento cualquiera. Pero no es tan sencillo, porque lugar y tiempo es algo que depende también de las culturas. Por ejemplo: Yo tenía una amiga argentina, y cuando quedábamos para vernos otro día yo le decía "Bueno, pues, Vir, podemos quedar el miércoles”, “¿A qué hora?", preguntaba ella, "Pues a media tarde", respondía yo, y ella, indefectiblemente, decía "¿qué es media tarde?". Claro, no es lo mismo media tarde si se almuersa a las doce, y se come a las siete, que si se come a las tres y se cena a las diez. Yo he tenido alumnas polacas, y daba una clase de dos a tres y media, para ellas era una clase de tarde, de media tarde, mientras que para mis alumnas catalanas era una clase de mañana, de última hora de la mañana, a la que venían sin comer; mientras que las chicas polacas ya estaban a punto de merendar, porque ya habían comido a las doce o las once y media. Por lo tanto qué es media tarde, vemos que el concepto de tiempo también puede variar. Por ejemplo, en México, cuando alguien dice "¿nos vamos?” y contestan "luego", hay que levantarse e irse. Sin embargo a mí me dicen "luego", y me espero y pienso "bueno, pues ya me dirán cuándo". Pero es que, en México, "luego" quiere decir "ya", "al instante" (uso que, por cierto, aún se mantiene en ciertos lugares de Castilla). Ahora bien, si a la pregunta "¿Cuándo nos vamos?" responden "ahorita", yo pienso "Bueno pues ya me voy" y me levanto, pero resulta que no, que "ahorita, ahoritita ahoritita" es dentro de un ratito. No solo el tiempo es cultural, sino las maneras de nombrarlo, lo que simboliza lingüísticamente esas diferencias.

Refiriéndose al espacio, Duranti (2000 [1997]), un etnógrafo de la comunicación, habla de las diferencias entre lo que se considera la parte delantera y trasera de la casa en cuanto a su función social. Aquí hablamos del "recibidor", que es la entrada de la casa, el lugar donde a la gente que llega se la recibe, se saluda, y luego ya se pasa a la sala, a la cocina, al comedor, según se tenga costumbre. Pues bien, Duranti explica que en Samoa el lugar donde la gente se saluda es lo que para nosotros sería la parte de atrás de la casa. Por lo tanto se entra en la casa se pasa, se pasa, se pasa, y cuando se llega al final entonces se saluda. Imaginad que ahoya yo llego a vuestra casa, me abrís la puerta y yo paso directamente, sin decir nada y cuando ya llego a la cocina o a la sala, ya empiezo a saludar. Diríais "ipero adónde va esta señora?". Por el contrario, si llegamos a una casa en Samoa y empezamos a saludar nada más entrar se apreciaría como una agresión. Vemos, pues, que también el espacio puede ser interpretado de forma diferente según las culturas.

Dentro de esos conceptos de tiempo y espacio, hay que considerar que existen fronteras externas y fronteras internas. Pensemos en este salón de ac- 
tos, aquí hay unas fronteras externas: las paredes, el techo, el suelo, la puerta, ¿pero aquí no hay una frontera interna cual "foso de cocodrilos"? Veamos ¿quién se atreve a salir del patio de butacas, subir a la tarima donde estoy yo, sentarse a mi lado y decir: "Mira, Amparo, me voy a poner a escuchar aquí ¿vale?"? Aquí hay una frontera interna evidente ¿Y por qué nos interesan esas fronteras internas para describir la interacción humana? Porque otorgan deberes y derechos respecto al uso de la palabra. Por ejemplo, en estos momentos, quien tiene el derecho, pero también el deber de hablar, soy yo. Y si ahora me callo pensaréis que me ha pasado algo ¿no? Porque se está transgrediendo una norma de comportamiento comunicativo que a mí me otorga ahora un derecho, pero también un deber. Pensemos en una sala de juzgados. Hay una serie de fronteras internas que delimitan el lugar de la acusación, el lugar de la defensa, el del juez y, si hay jurado, el del jurado. Y cuando le toca hablar a la acusación tiene que acusar, y la defensa, cuando habla, tiene que defender. Es decir, que esas fronteras internas otorgan derechos y deberes y también formas de hablar e incluso contenidos.

Ahora bien, en el caso de la conversación espontánea esas fronteras son muy difusas, porque, como hemos visto al leer algunas de las características que señalaban Schegloff y Jefferson, casi en cualquier lugar se puede producir una conversación espontánea.

El otro subcomponente de la "situación" es el la "escena psicosocial". Bajo esta denominación nos referimos a que las personas, en una comunidad, otorgamos una significación social prototípica a esa escenificación, a ese lugar y a ese tiempo, un significado simbólico. Por ejemplo esta sala y esta hora la asociamos con una conferencia, no con una fiesta punky. Aunque se podría dar, quién sabe. Si el rectorado lo permite, si hay estudiantes suficientes para organizarla y se responsabilizan de lo que pase, ¿por qué no? Así pues, asociamos a una sala de juzgados, un juicio; a un mercado tradicional, interacciones de compra-venta; a un templo, diferentes rituales: misa, confesión, sermón, oración, plegaria; a un aula, por ejemplo, explicación, examen, trabajo en grupo.

En el caso de la conversación espontánea, como decía, cualquier lugar puede convertirse en un escenario posible. Aquí mismo, incluso ahora tal vez por ahí detrás puede que alguien esté manteniendo una conversación espontánea en voz muy bajita, eso sí, con la persona que tiene más cerca, y en cuanto la conferencia se acabe y haya un descanso, esto se convierte en un lugar en que se pueden producir — y con toda seguridad se produciránconversaciones cotidianas, coloquiales, espontáneas. Ahora bien, los lugares más prototípicos donde se producen habitualmente conversaciones espontáneas, al menos en nuestro entorno, podrían ser la cocina o el comedor de casa, una cafetería, el pasillo de la facultad, un paseo, etc... 
A continuación vamos a ver algunos ejemplos de confusión en que estos prototipos, estas normas que estoy definiendo fallan. Y ¿por qué es interesante fijarnos en lo que ocurre cuando algo falla? Porque de la misma manera que el conocimiento de la anatomía del cuerpo humano se ha desarrollado sobre todo a través del estudio de la enfermedad, de ver lo que funciona mal, para entonces detectar qué es lo que no funciona como debería y descubrir cómo debería de funcionar, también si nos fijamos en los malentendidos y en los momentos en que las expectativas se rompen en la interacción humana, podemos avanzar más en ver cómo esperamos que funcione habitualmente.

En una oficina bancaria, en el cinturón industrial de Barcelona, llegó una señora y se produjo el siguiente diálogo entre ella y un trabajador de la oficina:

\footnotetext{
- Oiga, que vengo a que me digan adónde le ha tocado a mi hijo hacer la mili - Pero señora, que eso no es aquí

-Que sí, que a mi me han dicho que en la caja me lo dirían
}

¿A qué "caja" se refería? A la "caja de reclutas", pero para ella, para esta señora la "caja" era la "caja de ahorros", no conocía otra caja. Y por eso ella fue a esa oficina bancaria y le tuvieron que decir que no, que era otro lugar.

En esa misma oficina bancaria — que debía ser lo que ahora se llama un "observatorio" genial-, antes de que se pusieran las mamparas de seguridad, llegaba a menudo hacia la una, una y media, un señor que ya conocían, porque era del barrio, quien, apoyándose en el mostrador, decía "Un vino". Claro, este señor ya venía de otros locales en los que existía esta frontera interna en forma de barra, y como ya no veía mucho más allá de la barra, la identificaba simplemente con otras que había en bares de los que venía y pedía "un vino"; entonces le decían "Señor Benítez, venga, va, váyase a su casa que ya ha bebido demasiado", y el señor se iba.

Todo esto es real, sin embargo ahora os contaré un chiste para ver cómo funciona el contexto como guía que nos orienta y nos limita la producción y la interpretación de enunciados.

Un joven entra a un bar y se acerca a la barra; se le acerca el camarero y le dice: "¿Qué va a ser?", el joven contesta: "Abogado", el camarero dice: "Que qué quiere", dice el joven: "Acabar la carrera, encontrar trabajo, comprarme un piso...". El camarero insiste, un poco impaciente: "Que qué va a tomar". El joven, dándose cuenta, responde: "Ay, ay, ay, perdone, perdone ¿qué hay?", a lo que el camarero contesta: "Pues ya ve, aquí, trabajando".

Si nos fijamos, todas esas respuestas son posibles respuestas a esas preguntas, pero no en esa situación, no en ese escenario, no en ese contexto. 
Eso es una prueba en forma de chiste ingeniosísimo, para comprobar que la situación, el escenario, nos guía, nos condiciona, nos restringe y nos orienta en la producción e interpretación de los enunciados.

Otro ejemplo: alguien dice: “Tiene hora?” y le responden: "Sí”. A todos nos viene a la mente que si alguien dice “Tiene hora?” está queriendo decir: "Quiero que me diga qué hora es". De acuerdo, pero ¿y si estamos en un consultorio médico y quien dice “iTiene hora?” es la persona encargada de la recepción, y lo que está contestando la segunda es que sí, que tiene cita previa? Entonces sí que funciona ese diálogo. He aquí otra prueba de cómo el contexto nos orienta, nos restringe, nos ayuda en la producción e interpretación de enunciados.

Hablemos del siguiente componente: los participantes; lo que nos interesa son sus características socioculturales: la edad, el sexo, el estatus, los papeles que puede desempeñar, su bagaje de conocimientos, su repertorio verbal... pero, especialmente interesantes son los conceptos de "imagen" y "territorio", que fueron acuñados y desarrollados por el sociólogo de la interacción Goffman (1967 [1970], 1979 [1971]). Goffman plantea que toda persona tiene una imagen positiva y una imagen negativa. La imagen positiva es la que apela a la simpatía, a la solidaridad, a la intimidad, a la cooperación... Mientras que la imagen negativa es la que apela al deseo que tengo de que se me respete, de que se mantenga la debida distancia. Claro, en cuanto dos personas se ponen en contacto, ya tenemos cuatro imágenes en funcionamiento (como en el chiste del psiquiatra, que entra un paciente y el psiquiatra le dice: ¿Qué le pasa?”. Y contesta: "Creo que tengo doble personalidad". Y dice el psiquiatra: "Pues siéntese y hablaremos los cuatro"). Porque es verdad, todos queremos recibir simpatía, solidaridad, pero a la vez que se nos respete y que se mantenga una cierta distancia.

Graciela Reyes (1990) plantea que una cosa es la imagen que quiero dar, otra la que doy y otra la que la audiencia está dispuesta a aceptar de mí. Supongamos que yo quiero dar la imagen de una profe simpática, abierta, flexible; pero resulta que doy la imagen de una profe loca. Y claro, la audiencia no está dispuesta en absoluto a aceptar a una loca, aquí, dando una conferencia. Eso significa que hay que calcular bien, hay que ajustar, hay que negociar las imágenes.

En cuanto al territorio, toda persona lleva una especie de muralla flexible alrededor que, si lo que quiere es potenciar la imagen positiva, traerá hacia sí para que la otra persona se pueda acercar. Pero si lo que quiere es potenciar la imagen negativa, el respeto, la distancia, la alejará para que la otra persona mantenga esa distancia, respete ese espacio.

Ejemplos de expresiones relacionadas con la imagen y el territorio existen. Por ejemplo "En esto no te metas", "Metí la pata" (cuando digo "metí la 
pata" es que dije algo que era del todo inconveniente porque me metí en el terreno que no debía); "De abi no pases", "Ponte en mi lugar", "Se pasó tres pueblos", "Es que es una persona que no sabe ponerse en su sitio", "No te hablo como tu profesora, sino como tu amiga". Vemos que en las lenguas existen expresiones que dan cuenta del funcionamiento de los conceptos de "imagen" y "territorio" en la vida cotidiana.

Presentaré a continuación algunos ejemplos de cómo la imagen que se tiene de otra persona puede llevar a malentendidos; ahora, cuando los cuente seguramente parecerán muy divertidos, pero que pueden llegar a ser dramáticos. No sé si conocéis la expresión asturiana, especialmente gijonesa, " "Vete a ver la ballena?". Hace muchos años varó una ballena; todo el mundo dejó lo que estaba haciendo; si estaba hablando con alguien, lo dejó y se fue a ver la ballena. Y entonces quedó ese dicho, "iVete a ver la ballena!", para significar "vete a paseo", "déjame en paz", "vete de aquî". Cuando esa expresión comenzó a caer en desuso entre la juventud, una profesora de secundaria, de lengua y literatura, me comentaba:

Fíjate lo que me pasó, estaba yo dando clase y había un alumno que estaba enredando, enredando, y yo ya me cansé y le dije: "Fulanito, vete a ver la ballena”. Y efectivamente el chico se levantó y se fue. Pero, al cabo de diez o doce minutos volvió y le dije: "Pero ¿qué haces aquí?", y me contesta: "Oh, ya fui a ver a la jefa de estudios".

Claro, la profesora decía — sin haber leído a Goffman- "pero ¿cómo puede pensar que yo voy a llamar ballena a la jefa de estudios? con lo delgadita que ye"; como si eso lo arreglara. El caso es que ese chico tenía una imagen distorsionada del papel de esa profesora.

Otro ejemplo absolutamente real. No sé si conocéis Barcelona y si habéis utilizado el metro en esa ciudad. Un señor va a un hospital a que le hagan una revisión médica. Le dicen que tiene que hacerse un análisis de orina, le dan el botecito correspondiente y dice: “¿adónde he de ir?". La enfermera le contesta: "La línea roja y al fondo". Entonces el señor se va y empieza a tardar. La enfermera estaba preocupada, "tendrá algún problema", pasa media hora y no llegaba. El caso es que al final llega el señor absolutamente enfadado. Quienes os reís seguramente os reís porque sabéis que en Barcelona existe una línea de metro llamada "línea roja", que acaba en uno de los extremos, en una parada que se llama "Fondo". Y el señor, cogió la línea roja, llegó hasta la última parada, salió y empezó a buscar algún sitio donde él creía que lo habían enviado para hacerse el análisis. Claro, cuando volvió y se lo contó a la enfermera, a la enfermera le dio un ataque de risa. Bien, este señor se fue al servicio de atención al usuario y denunció al personal sa- 
nitario por dar mal la información y por reírse de los pacientes, y con toda la razón. Porque simplemente este señor tenía la imagen, que muchos tenemos, de lo que puede ocurrir en ciertos lugares de la seguridad social: vas a un sitio, entonces te envían a otro y así vas siguiendo una especie de excursión planetaria por diferentes centros, y al final pues más o menos todo hasta llega a salir bien.

Pasemos a hablar del componente denominado "instrumentos". Me interesaría señalar algunos aspectos, aunque sé que en otras conferencias se van a desarrollar con más detalle; por eso ahora sólo haré algunos apuntes.

El "canal" puede ser oral, escrito, audiovisual, icono verbal... En el caso de la conversación espontánea diríamos que el canal es oral, cara a cara, aunque, como ya señalaba el profesor Regueira, actualmente estamos accediendo a otros canales que vinculan formas de comunicación casi igualmente espontáneas o informales, pero a través de la escritura, de una escritura, eso sí, coloquial e informal: los mensajes sms, el Messenger, los chats, etc... Éste es un tema de gran interés porque es una de las fronteras más claras y emergentes entre la oralidad y la escritura.

A parte del canal, tenemos que pensar en las variedades de habla: lengua o lenguas y variedades de cada lengua (geográficas, sociales y funcionales). Diríamos que en la conversación espontánea, cuando se dispone de más de una lengua, se elige aquella que se considera más adecuada en función de aquello que se pretende. Normalmente se mantiene la variedad dialectal geográfica propia. En cuanto a la variedad social depende de la cara, de la imagen, que queramos presentar. Yo me puedo querer manifestar más como profesora, como amiga, como hija, como esposa... En cuanto a los registros, el típico es el coloquial aunque puede haber ciertos cambios.

Lo que es interesante ver es que en cualquier evento comunicativo seleccionamos de entre nuestro repertorio verbal y comunicativo, y, en el momento de abrir la boca, hemos de elegir una lengua, una variedad geográfica, una variedad social, un registro. Otra cosa es que podamos alternar consecutivamente lenguas diferentes, registros diferentes. Pero cuando eso hacemos, esos cambios entre lenguas y variedades siempre tienen un significado social, un significado metafórico, porque si yo elijo una cosa, dejo de elegir las demás, y si hago eso — consciente o inconscientemente- por algo es, como demuestran los múltiples estudios sobre elección y alternancia de lenguas y variedades. Vosotros que manejáis dos o tres lenguas y varias variedades de cada una, cuando cambiáis de una a otra, por qué lo hacéis, para qué, cuando os hablan en una lengua o variedad y de repente cambian a otra ¿qué asociáis con esos cambios?

A parte de la lengua y las variedades, está todo aquello que acompaña a la palabra, y aquí sí que me quisiera extender algo más. Lo que acompaña 
a la palabra son las "vocalizaciones", la "kinesia" o "cinesia" y la "proxemia" (Poyatos, 1994). Las vocalizaciones son esos ruidos de asentimiento, de rechazo, de asco, de incomprensión, del tipo "ahhh, tsee, bah..." Estas vocalizaciones no son palabras pero son altamente significativas desde el punto de vista comunicativo, y se dan muchísimo en la conversación espontánea. Kerbrat-Orecchioni, una analista del discurso francesa, les llamaba en francés "grondisèmes", haciendo un paralelismo con otras unidades de la lengua: "phonèmes", "morfèmes" y... "grondisèmes"; en español se podría traducir por "gruñemas"; aunque, como dice Carlos Lomas, habría que distinguir los "gruñemas" de los "gocemas", porque no es lo mismo decir "buagg" que decir "ahhh"...

Todo esto, que ni siquiera tenemos en cuenta como algo interesante cuando estudiamos la oralidad, es fundamental en la interacción comunicativa, y lo veremos con algunos ejemplos en los que se apreciará que, además, estas vocalizaciones cambian según las lenguas o las culturas.

Antes de seguir con otro ejemplo, os planteo una cuestión: imaginad que yo os hago una pregunta, me contestáis y yo hago " ha". ¿Qué entenderíais por ese " $h a$ "? ¿Que no estoy muy de acuerdo? ¿Me equivoco si digo que lo interpretaríais como símbolo de desacuerdo? Algo así como "pues vaya", "iqué dices!".

Pues bien, una profesora de Estados Unidos fue a Barcelona a recoger material para su tesis doctoral sobre lengua, ideología y cultura en Cataluña; yo no la conocía, pero a través de amigos comunes, como yo tenía una habitación libre, vino a vivir a mi casa. Ella y yo nos comunicábamos en castellano aunque ella aprendió el catalán en seguida. En aquella época mi conocimiento del inglés era limitado, como decía Eugenio: “¿Usted domina el inglés?", "Pues si es bajito y se deja...".

Bien, pues esta chica de Estados Unidos me tomó como su informante clave - tal como se denomina en antropología a la persona de confianza que se toma como una primera fuente de información que luego se contrasta con otras- y me preguntaba a mí sobre diferentes cosas y yo le contestaba, por ejemplo me decía: "Mira, hoy he ido a tienda y he encontrado que una hablaba en catalán, el otro no sé qué, y no sé qué ¿qué te parece a ti?" yo le contestaba: "pues pienso que blablablá blablablâ" y ella me decía: "ba". Y yo, al oír esa vocalización, le decía algo como: "mira, es lo que yo pienso, no sê". Al día siguiente, de nuevo: "Oye, que he leído en el periódico, que pasa tal y cual, ¿qué es esto?", y yo: "pues mira yo creo que es tal y tal y tal", y ella " "ha". Y yo, ya un poco enfadada: "bueno, pues eso es lo que yo creo, pregúntalo a otra persona". Claro, se me dispararon todos los estereotipos: "jestos americanos, qué se han pensado, que lo saben todo, entonces para qué vienen y preguntan!". Total, que en casa la comunicación era un poquito tensa 
ya. Al cabo de unos meses, vinieron unos amigos suyos de Estados Unidos y me invitaron a cenar. Y yo, como decía, en inglés, aquello de "the flowers in the garden", "tomorrow in the beach", y poco más. Seguramente conocéis la situación de estar en una cena informal y todo el mundo hablando y tú, pues, aquello de que si se ríen te ríes, pensando "se están riendo de mí, yo aquí haciendo el imbécil”, pero, bueno, yo, allí, poniendo cara de inteligente cuando los otros ponían cara de lo que yo creía que era cara de inteligencia... El caso es que en un momento determinado se produce el " $h a$ " y yo, como el perro de Paulov, salivando... pero no pasa nada, y siguen. Y otra vez " $b a$ " y tampoco pasa nada, hasta que, por fin, al cabo de unos cuantos " $h a$ ", consecutivamente hicieron la traducción lingüística, y era "ba, how interesting" o sea "job! qué interesante". En ese momento, yo rebobiné y vi la película desde el otro lado: "la chica americana estará pensando: "qué raros son estos catalanes, que les dices que algo de lo que te comentan es interesante y va y te lo repiten enfadados", que es lo que yo hacía. Lo comenté con ella, nos reímos y... seguimos siendo amigas después de treinta y cinco años. Y esto es algo que he ido comprobando, porque, claro, podía ser una peculiaridad de esta persona, pero no es así, es una vocalización que "en inglés" tiene ese significado.

Utilizando también como comparación el inglés y el castellano —en esto el gallego y el catalán son muy semejantes-, yo siempre digo que si a alguien le están enseñando inglés, le tendrían que enseñar que cuando le preguntan, aunque sea su nombre, tiene que empezar la respuesta diciendo "eee..." y terminar con un tonema ascendente. Por ejemplo, si alguien me pregunta: "what's your name?", respondería: "eee... amparo/". Cuando yo estaba en Estados Unidos y preguntaba a alguien su nombre y me contestaba: "eee...¿¿Patrick?", yo pensaba, "pues no sé, tú sabrás". Nos encontramos ante formas de entonación, patrones de respuesta diferentes. Entonces si a una persona que está aprendiendo inglés le enseñan que sobre todo antes de contestar haga "eee...", queda genial, queda muy inglés. Ahora, cuando un anglófono está estudiando nuestras lenguas, se le tendría que enseñar que, sobre todo, cuando responda, no empiece diciendo "eee..." porque queda muy extraño. Es decir, que esta serie de vocalizaciones funcionan en unas lenguas y no en otras.

Por ejemplo, en Senegal. En Senegal, donde estuve participando, junto con Luci Nussbaum, en un trabajo de cooperación para un programa de alfabetización comunitaria de adultos, observaba que cuando las personas hablaban entre ellas producían un sonido del tipo "tche tche". Algo que nosotras asociábamos con el ruido que hacemos o bien cuando se nos queda un trocito de espinaca o un trocito de pulpo entre los dientes "tche tche", o también algo que asociábamos a una determinada manera de lla- 
mar a algunos animales "tche tche", "tche tche". Pero ni había espinacas entre los dientes, ni había animales alrededor. Hasta que descubrimos que esa era una vocalización de lo que se llama retroalimentación, feedback, que simplemente servía para decir "te escucho, sigue, sigue, te escucho, te escucho". Entonces pensamos y nosotras ¿qué hacemos en lugar de esa vocalización? Lo que hacemos es "aha aha $\mathrm{mm} \mathrm{mm}$ ". Y como lo que no es habitual se oye como amplificado, decíamos "pensarán que somos unas ansiosas o algo raras diciendo aha aha $\mathrm{mm} \mathrm{mm}$ ". Por eso el concepto normalidad, lo que es normal, hay que ponerlo bajo sospecha inmediatamente, porque lo que es normal para mí, lo es para mí en mi entorno más inmediato, pero en cuanto salgo de ahí, hay otras formas de hacer, de decir y... de vocalizar.

Hablemos ahora de la "cinesia"; los gestos son diferentes según cada tipo de evento. En la conversación espontánea, en nuestro entorno, hay mucho movimiento de manos, te toco, me tocas, depende dónde, cuándo y cómo, pero sí que hay contacto físico y contacto visual. Eso es así en las conversaciones. En esta conferencia incluso puede que yo esté gesticulando demasiado porque no empezaré como en un noticiario; en un noticiario como mucho quienes lo presentan tienen un bolígrafo, que a veces piensas "si ahora le quitas el bolígrafo al locutor, se cae", porque es casi como una columna a la que se ha agarrado. Pero hay muy pocos gestos: arreglan los papeles — que no miran, porque tienen el "pronter"- y poco más, pero no nos podemos imaginar, excepto a Carrascal en su época, que dijeran echándose las manos a la cabeza: "iAy, lo que ha pasado hoy, si yo les cuento no se lo van a creer!". Eso no es propio de un noticiario, y sí lo es de una conversación espontánea.

Además los gestos son diferentes según los grupos sociales; por ejemplo hay un estilo de gestos más masculino o que identificamos como masculinos, y otros que identificamos como femeninos; no digo de hombres o de mujeres, sino masculinos o femeninos, porque hay muchas formas de ser hombres y de ser mujeres, porque hay hombres que tienen una gestualidad más femenina y mujeres que tienen una gestualidad un poco más masculina. Eso puede significar determinadas opciones sexuales o no. Pero sí que es verdad que existen estudios que demuestran que los gestos típicamente masculinos son gestos muy abiertos, con los brazos muy separados del cuerpo, las piernas también, el paso más "decidido". Mientras que el estilo gestual femenino sería un estilo más recogido, con movimientos sin despegar los brazos del cuerpo, los pasos más cortos, la forma de sentarnos también es diferente. Lo que es interesante es ver que la trasgresión de la mujer hacia el estilo masculino está mejor aceptada que la trasgresión del hombre hacia el estilo femenino. Es decir, si una mujer que entra y dice, con paso decidi- 
do y gestos abiertos: "bueno, vamos a ver, hoy tenemos que hablar de cosas muy importantes" pensamos: "jcaramba, qué mujer!". Ahora bien, si es un hombre, y con gestos recogidos, femeninos, dice: "bueno, hoy lo que tenemos que hacer es importantísimo"... Si ahora os reís como lo estáis haciendo, es porque la sociedad acepta más la trasgresión hacia lo masculino que la trasgresión hacia lo femenino, porque históricamente - y esto, afortunadamente, está cambiando- lo masculino era la imagen pública, la imagen del poder.

En cuanto a la "proxemia", que se refiere a la posición de los cuerpos y a la distancia entre ellos, también esto varía mucho según las culturas. En Dakar, en Senegal, observamos a dos policías, vestidos al estilo francés, pero de Dakar, que estaban haciendo la ronda cogidos de la mano. Imaginan a una pareja de cualquiera de las diferentes fuerzas de seguridad —locales, autonómicas, del estado- que hay haciendo la ronda con las manos entrelazadas... Otro aspecto se refiere a la costumbre de tocar o no mientras se habla, tocar o no cuando quieres pasar por detrás de alguien. Yo tenía una alumna alemana que me dijo: "Estoy harta porque aqui me empujan". Yo le pregunté: “Quién te empuja, corazón?", a lo que ella me respondió: "Sí, porque estoy en el pasillo hablando y llega alguien por atrás y baam, me empuja". Y yo le dije: "Vamos a ver, cariño, ¿no será que te dicen, 'perdona' y te tocan un poquito en la espalda?". Y ella: "Pues eso, me empujan". Y yo: "no mujer, eso no es que te empujen, es solo que te apartan un poquito para pedirte permiso". Y ella: "Pues que me diga 'paso', pero que no me empuje". Lo que para nosotros es simplemente un leve roce, para pedir permiso para pasar, para ella era un empujón.

Yo enseñé español para principiantes en Estados Unidos, y un día estaban haciendo una simulación de papeles, esto que se llama "rol play", y se suponía que un chico y una chica tenían que representar que eran un matrimonio y se encontraban para ir a un restaurante. Y se encontraron, pero a metro y medio, y yo les dije: "no, cariño, en español asi”, y los acerqué a unos treinta centímetros.

Antes de ir yo a Estados Unidos con una beca, una señora de allí nos reunió y nos explicó normas y comportamientos típicos que teníamos que tener en cuenta, y una de ellas era precisamente el de la distancia de los cuerpos. Nos dijo: "la distancia en Estados Unidos para conversar en la calle, en un pasillo, es más o menos la extensión de un brazo y un poquito más", que yo pensé: "claro, como alli todo es muy grande", porque según en qué calle del casco viejo de cualquier ciudad nuestra te pones así y te atropellan seguro, o empieza a pasar todo el mundo por en medio. Esta señora nos contó lo siguiente: 
La primera vez que fui a Madrid, había una party, entonces yo estaba hablando y se me acercó un chico y se me acercó (a poco más de medio metro). Entonces yo ¿qué hice? di un paso atrás, y él ¿qué hizo? dio un paso adelante, ¿yo qué hice? di un paso atrás ¿y él? dio un paso adelante" y dice, "hasta que choqué con la pared... pero ¡no pasó nada!”.

Claro, inconscientemente, cada uno buscaba la distancia que le era habitual, y ella pensaba que él se le estaba abalanzando y no, una vez ya ella chocó con la pared, él ya no se acercó más.

Un tema interesantísimo para estudiar es el de los saludos, porque en ellos se da conjuntamente la palabra, la cinesia, la proxemia, las vocalizaciones, todo. Veamos algunos ejemplos. Los chicos, en nuestro entorno — vuelvo a hablar en general, porque hay muchas excepciones-, cuanto más se quieren más se pegan y más se insultan: "Joder, macho, ¿como estás?, jcagüen la puta! ¡cuánto tiempo que no te veo!” ¿sí o no? Las chicas, nos damos besitos: "iAy, qué mona estás, hola, cuánto tiempo sin verte!" ¿sî́? En fin, hay diferencias, claramente.

Yo estuve en Burkina Faso y recuerdo que un día yo iba con un hermano mío que trabajaba allí en cuestiones de desarrollo agrícola, y yo lo acompañaba con gente de allí a visitar diferentes aldeas, y siempre la escena era la misma. Llegábamos, saludábamos, yo sonreía, porque no sabía decir ni buenos días en la lengua de allí, el Bissa; hasta que un día me decidí a saludar, había oído muchas veces ya el saludo, y lo repetí. Entonces los hombres, que eran los que nos recibían — detrás estaban las mujeres, que después ya venían a saludar también-, se quedaron con los ojos muy abiertos y empezaron a reírse, y las mujeres, por detrás, por el suelo ya, directamente, de la risa. ¿Qué había hecho yo? Pues saludar como un hombre, es decir, como si en vez de decir "buenos dias, encantada" hubiera dicho "joder, macho, cómo me alegro de conocerte", eso había hecho.

Un caso especial es el de los besos: ¿̇uno, dos, tres, cuatro, sólo rozando la mejilla, de pueblo, de esos "muaks muaks"? Una chica inglesa dijo: "bueno, ya sé que son dos besos, pero i¿por dónde se empieza??". Claro ¿lo habías pensado alguna vez?, ¿alguien os había dicho en la infancia: "acuérdate de que cuando vayas a besar a alguien, tienes que dirigir tu mejilla hacia su mejilla derecha"? Bueno, pero eso aquí, porque en Italia "se empieza" por la izquierda. Y, claro, si no se coordinan los movimiento, puede pasar que se vaya cada uno para un lado diferente o producirse un encuentro tal vez no deseado... En Latinoamérica o en Canarias se da sólo un beso, con lo cual tú das un beso, la otra persona ya pasa y tú te vas casi a besar el marco de la puerta...

En fin, no voy a extenderme más, aunque hay muchos otros aspectos interesantes que se podrían tratar: las finalidades, las normas de interacción y 
de interpretación... En cualquier caso, lo que vemos, repito, a través de estos ejemplos, es la fragilidad de la interacción comunicativa, sobre todo cuando es coloquial, espontánea.

¿Y cómo es posible que nos vayamos entendiendo? ¿Qué vayamos interpretando adecuadamente las intenciones de los demás y que manifestemos las nuestras con éxito?

Gumperz plantea que cuando conversamos captamos y producimos lo que él denomina indicios de contextualización. Se trata de pistas que pueden ser léxicas, sintácticas, prosódicas, o no verbales. Un determinado tono de voz, un ritmo especialmente acelerado o lento, una determinada selección léxica, la elección de un tipo de construcción sintáctica, de un registro o de un estilo, o el cambio de una lengua a otra, la selección de una variante fonética —así como una mirada, una vocalización o un contacto físicocontribuyen a la creación de un contexto específico en el que nos situamos para dar sentido a lo que está pasando a través de realizar las inferencias apropiadas y, de esa manera, interpretar y producir los enunciados de manera adecuada. Porque la comunicación no es ni más ni menos que un continuo proceso de inferencia.

Y cuando no se realiza el proceso inferencial adecuado es cuando surge el malentendido que, en muchos casos — como hemos ido viendo en los ejemplos- es de origen sociocultural. Aplicamos marcos de referencia distintos que hacen que interpretemos de manera diferente lo que se está diciendo y lo que está pasando.

Por eso una de las líneas de investigación que más se ha desarrollado desde la perspectiva etnográfica es la de la comunicación intercultural. También la etnografía de la comunicación ha dado grandes resultados en los estudios del discurso en el aula. (Pensemos, también, que está en la base de los enfoques comunicativos de la enseñanza de las lenguas).

Para terminar, quisiera dejar claro que mirar de esta manera las producciones discursivas es altamente útil y provechoso, porque nos permite entender de qué manera a través del discurso — entendido como actividad social y como vehículo para llevar a cabo la mayor parte de las actividades sociales-, nos vamos construyendo como seres sociales, con identidades complejas y variadas. Mirar así la vida social nos ofrece un panorama complejo, sutil y variado. Tan variado y tan rico como la vida social misma.

\section{REFERENCIAS BIBLIOGRÁFICAS}

Boas, Franz (1911): "Introduction", in Handbook of American Indian languages. Washington D.C.: Smithsonian Institution, 1-83. 
Duranti, Alessandro (2000 [1997]): Antropología lingüistica. Cambridge: Cambridge University Press.

Calsamiglia, Helena \& Amparo Tusón (2007 [1999]): Las cosas del decir. Manual de análisis del discurso. Barcelona: Ariel.

Goffman, Erving (1970 [1967]): Ritual de la interacción. Ensayos sobre el comportamiento cara a cara. Buenos Aires: Tiempo Contemporáneo.

Goffman, Erving (1979 [1971]): Relaciones en público. Madrid: Alianza.

Goodenough, Ward (1964 [1957]): "Cultural anthropology and linguistics", in Dell H. Hymes (ed.): Language in culture and society. New York: Harper and Row, 36-39.

Hymes, Dell H. (1972): "Models of the interaction of language and social life", in J. J. Gumperz \& D. H. Hymes (eds.): Directions in sociolinguistics. The ethnography of communication. New York: Basil Blackwell, 35-71.

Jakobson, Roman (1984 [1960]): "Lingüística y poética", in Ensayos de lingüistica general. Barcelona: Ariel, 347-395.

Poyatos, Fernando (1994): La comunicación no verbal, I. Cultura, lenguaje y conversación. Madrid: Istmo.

Reyes, Graciela (1990): La pragmática lingüistica. El estudio del uso del lenguaje. Barcelona: Montesinos.

Sacks, Harvey; Emmanuel A. Schegloff \& Gail Jefferson (1974): "A simplest systematics for the organization of turn-taking in conversation", Language 50, 696-735.

Sapir, Edward (1949 [1932]): "Cultural anthropology and psychiatry", in Culture, language and personality. Selected writings. Ed. por David G. Mendelbaum. Berkeley: Univ. of California Press, 509-521.

Saville-Troike, Muriel (1989 [1982]): The ethnography of communication. An introduction. London: Basil Blackwell.

Tuson, Amparo (1995): Anàlisi de la conversa. Barcelona: Empuries. Trad. cast. Análisis de la conversación. Barcelona: Ariel, 1997. 